\title{
Cartografias lusitanas de Cecília Meireles: trajetos de viajante e observações de cronista
}

\author{
Karla Renata Mendes \\ Universidade Federal de Alagoas
}

\begin{abstract}
Resumo
Cecília Meireles é reconhecida por sua obra poética, sendo destacada como um dos principais nomes da poesia brasileira. Todavia, a autora possui também uma vasta produção em prosa. O presente artigo se propõe investigar uma das vertentes da crônica ceciliana — os relatos de viagem. Trata-se de textos que revelam uma Cecília Meireles viajante pelos mais diferentes lugares do mundo, em contato com diferentes culturas e descrevendo sua percepção desses espaços e experiências. Assim, procura-se evidenciar como se dá a construção do relato de viagem ceciliano em uma crônica sobre Portugal, analisando aspectos dessa vivência que perpassam por um olhar subjetivo e particular da paisagem observada.
\end{abstract}

Palavras-chave: Cecília Meireles; crônica de viagem; Portugal.

\begin{abstract}
Cecilia Meireles is recognize for her poetic work, and is one of the main names of Brazilian poetry. However, the author also has a vast prose production. This present article intents to investigate one of the versants of cecilian's chronicles - the travels reports. They are the texts which reveal a peregrine Cecilia Meireles in different places from the world, in contact with different cultures and describing their perception of these spaces and experiences. So, it intends to evidence how the cecilian travel report is built in a chronicle about Portugal, analyzing aspects of this experience that pass through a subjective and particular view of the observed landscape.
\end{abstract}

Keywords: Cecília Meireles; travel chronicle; Portugal.

Recebido em: 24/03/19

Aprovado em: 29/07/19

O nome de Cecília Meireles evoca à primeira vista, certamente, a associação direta à poesia. Reconhecida como uma das maiores escritoras da literatura brasileira, pensar em Cecília é lembrar-se de poemas emblemáticos como "Lua adversa" e "Retrato". Todavia, uma das outras faces cecilianas que há pouco mais de dez anos ganhou contornos mais definidos é a sua atuação como cronista. Dedicando-se ao gênero, fosse publicando em jornais ou apresentando textos em programas radiofônicos, a crônica fez parte da vida da poeta até o ano de seu falecimento, 1964. 
Dentre os volumes de suas crônicas publicadas, destacam-se aqui os três livros que reúnem textos agrupados sob a designação crônicas de viagem. Trata-se de relatos de seus percursos pela França, Estados Unidos, Holanda, Índia, Brasil, além de outros variados destinos. Perfazendo tais caminhos, a cronista confirmava a medida do universal que nela habitava, descrevendo com a mesma intensidade lírica os mais diferentes roteiros. Viajante, e não turista, como gostava de salientar, Cecília transmitiu a seu leitor as impressões de percursos sentimentais e não somente deslocamentos geográficos. Se é possível vislumbrar um amanhecer em Calcutá, também é possível observar uma tourada no México ou se encantar com uma visita ao Taj Mahal. Suas crônicas nos colocam em trânsito, fazendo-nos passear pelos mais diversos cenários e culturas. Em seus textos de viagem é possível atestar o fato de que, se o Brasil caracterizou-se como seu berço, o país tão admirado e divulgado, outros destinos foram adotados sentimentalmente por ela, ganhando retratos peculiares matizados por um caráter poético.

Dentre esses destinos afetivos, destaca-se aqui um de seus relatos de viagem a Portugal, país com o qual sempre manteve afinidades. Neta de açorianos, o espírito e a cultura lusitana sempre estiveram presentes na vida de Cecília Meireles. Muitos são os laços que a unem à terra de Camões. Assinala-se, por exemplo, seu primeiro casamento, com o português Fernando Correia Dias, as amizades mantidas ao longo de sua vida com escritores e artistas portugueses, a receptividade da crítica lusitana à sua obra e seu próprio envolvimento com a literatura portuguesa. Esses são alguns dos contornos dessa proximidade, que contribui para que o retrato do país em suas crônicas seja marcado por um tom subjetivo e lírico.

Transformando suas viagens em verdadeiras procuras espirituais, Cecília acabaria entrecruzando culturas, filosofias e modos de sentir e viver a experiência temporal. $\mathrm{O}$ presente seria valorizado em suas relações com o passado, instituindo-se então uma forma de atemporalidade. Consciente da transitoriedade que rege as dimensões da vida humana e da efemeridade de tudo, Cecília afirma a resistência do tempo de outrora no seu tempo, evocando-o e instaurando um diálogo entre as diferentes instâncias temporais. Seu "agora" escapa à estrutura linear alimentando-se por presenças antigas, figuras seculares e fatos históricos. Assim, no instante da viagem, localiza-se a eternidade do momento, uma vivência do tempo que revela afinidades com o pensamento oriental, com o "tempo interiorizado dos Upanishads que 'buscan la infinitud (bhûman) y la plenitud (pûrmân), cuyo simbolismo encuentran más em el espacio que en el tiempo" (apud GOUVEIA, 2002, p. 158). Conhecer Portugal através dos olhos de Cecília Meireles, e daquilo que registrou, é empreender uma travessia entre o real e o imaginado, entre o espaço observado e o sonhado, vislumbrando passagens de uma viajante que reinventa a si mesma e aquilo que descreve em cada um de seus textos.

Isso é o que ocorre com a crônica "Até Lisboa", publicada no Diário de Notícias, em 1957, e que se refere a uma viagem para Portugal realizada em dezembro de 1952. Nessa ocasião, Cecília Meireles pisava novamente em solo português, no entanto apenas para uma 
escala, pois a autora seguiria para outro destino por muito tempo desejado: a Índia. Lá, a convite do primeiro ministro Nehru, ela participaria de um Congresso sobre Gandhi, organizado em homenagem aos cinco anos da morte do líder pacificista, além de receber o título de doutor honoris causa pela Universidade de Delhi. Cecília e o marido retornaram a Lisboa, de onde regressariam para o Brasil, em junho de 1953, ano marcado pela publicação do Romanceiro da Inconfidência. Permanecendo na capital portuguesa por alguns dias, a poeta teve a oportunidade de realizar passeios, conhecer alguns lugares e rever outros em companhia do casal de amigos Diogo de Macedo e Eva Arruda.

Nessa crônica, descreve-se o percurso empreendido em uma viagem de carro desde Salamanca (Espanha) até Lisboa. Passando por várias cidades, ao longo de um trajeto de mais de $400 \mathrm{~km}$, Cecília registra a história dos lugares, seus personagens ilustres, as belezas, curiosidades e encantos dessas diferentes regiões. Nota-se que devido às raízes históricas muito fortes, evidenciadas em cada lugar que se visita, Portugal torna-se o cenário perfeito para a instauração de uma relação temporal dialética. Assim, constatam-se ligações entre o passado e o presente, e consequentemente entre as dimensões do efêmero e do eterno, do perene e do transitório, além de descrições que privilegiam um olhar mais lírico e poético sobre o espaço em questão.

A primeira cidade avistada neste trajeto é Guarda, conhecida, segundo Cecília, como a "cidade dos quatro ff: forte e feia, fria e farta" (MEIRELES, 1999, p. 95). Isso porque, popularmente, destacava-se a cidade como "forte" devido à posição geográfica, às muralhas e aos castelos construídos como defesa; "feia" por seu aspecto, "fria” por seu clima rigoroso devido à proximidade com a serra da Estrela, e "farta" por suas terras fecundas. Segundo a tradição, Guarda também era a cidade "falsa". Todavia, a população local, insatisfeita com as definições dos antepassados, acabou substituindo alguns termos como "feia" por "formosa" e "falsa" por "fiel”, mantendo as máximas até os dias atuais. Na ocasião de sua visita, Cecília já salientava que tais designações deveriam ser em "capítulo de rivalidades folclóricas e por fatalidade da rima...", reforçando a ideia com os versos de Lope de Vega: "Fuerza del consonante, a cuanto obligas!.." O fato é que, se a cidade era forte, feia ou farta, a cronista destaca que eles não o saberiam, mas fria tinham a certeza que não. Pois, "naquele meio dia de junho, brilha[va] sobre Guarda um sol dourado e quente: e [havia] tentações turísticas pelos quatro lados desta altíssima cidade, tão antiga" (MEIRELES, 1999, p. 95).

Dentre as "tentações turísticas" da cidade portuguesa "desponta a imagem de D. Sancho", a quem se atribuía a repovoação do lugar. A cronista menciona que o nome de D. Sancho "ficou ligado àquela famosa cantiga velha que a 'Ribeirinha', 'branca' e 'vermelha', talvez cantasse: Ai eu, coitada, como vivo/ en gran cuidado por meu amigo/ que ei alongado! muito me tarda/ o meu amigo da Guarda!” (MEIRELES, 1999, p. 95). Talvez a imagem de D. Sancho desponte com tanta veemência porque na cidade espalham-se algumas homenagens ao seu maior benfeitor. Uma delas é justamente uma placa de mármore no Centro Histórico, em 
que se encontram gravados os versos em questão como uma homenagem ao rei trovador. $\mathrm{Na}$ passagem do texto anteriormente citada, a cronista alude à "Cantiga da Ribeirinha", de Paio Soares de Taveirós, supostamente dedicada à amante de D. Sancho. Poeticamente, a autora inter-relaciona os poemas, supondo que a "Ribeirinha" "talvez cantasse", lamentando-se pelo seu "amigo" com os versos de "Ai, eu, coitada". A autoria destes versos foi por muito tempo atribuída a D. Sancho, como atesta Cecília Meireles, embora também se encontre Afonso X como seu possível compositor.

Inspirada pela imagem do rei "trovador", a cronista afirma: "E eis que vejo o rei D. Sancho, manto e saia de escarlata, por essas terras além... (Permito-me quase trovar.)" A trova composta por Cecília menciona as batalhas entre a coroa portuguesa e os mouros:

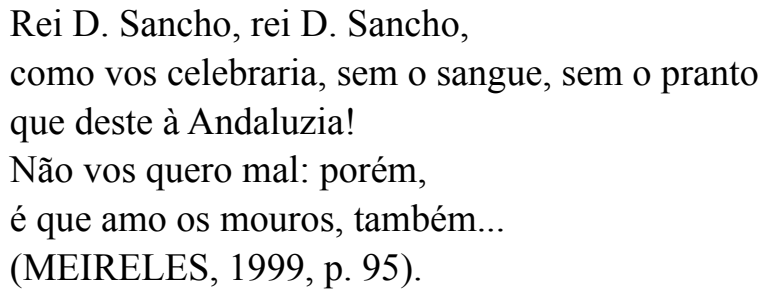

A identificação ceciliana com os temas e composições medievais é patente em muitos momentos de sua formação literária. Como afirma Eliane Zagury, em sua obra Cecília Meireles, a "Idade Média é um tempo ficcional propício para o devaneio ceciliano. [...] Não se trata de um simples devaneio, mas da retomada de um tempo e de um idioma repletos de raízes atendendo a um projeto de participação no universo ibérico do qual ela descende" (apud SANCHES NETO, 2001, p. L). Dessa forma, ao resgatar a imagem de D. Sancho como trovador e compor ela mesma versos ao estilo de trova, Cecília Meireles evoca a própria tradição portuguesa na qual historicamente se insere, e com a qual familiarmente se relaciona. Inserida neste contexto medieval, a cronista justifica o mal-estar relatado na pequena trova: "Embora rei do Algarve, D. Sancho, se foi mesmo o poeta do cancioneiro, compreenderá estas minhas inquietações sentimentais, ao passar pela terra de Guarda, onde é tão viva a sua sombra, — deixará que a minha, muito mais tênue, se aproxime de Celorico da Beira" (MEIRELES, 1999, p. 95). Cecília Meireles "dirige-se" a D. Sancho, mas seu discurso externa uma simpatia pelos mouros. Diante de tal impasse, a autora acredita que, mais forte do que o instinto bélico é a sensibilidade poética e, assim, espera que o rei a compreenda.

Referência constante nas "crônicas portuguesas" cecilianas, o termo "sombra" novamente é evocado aqui. Como afirma Leila V. B. Gouvêa, a palavra é usada de maneira "obsessiva na poesia lírica de Cecília Meireles" (2008, p. 111), remetendo a uma simbologia platônica do mundo. Na prosa, o vocábulo aparece, normalmente, para designar a imagem daquilo que permanece após a morte e a extinção do corpo físico. A "sombra", seja ela de Tomás Antônio 
Gonzaga ou de D. Sancho, reflete a subsistência de uma figura histórica e de seus feitos através dos séculos, a parcela eterna da existência que apenas alguns conseguem atingir. Por isso, a "sombra" do rei português é "tão viva", evocada em cada recôndito da cidade, enquanto a da autora é definida, modestamente, sendo "muito mais tênue".

Afastando-se de Guarda e da imagem de D. Sancho, a cronista passa pelo município de Celorico da Beira, ainda que duvide que este trajeto seja o mais acertado: O caminho parece mais longo, mas Cecília deixa-se conduzir pelas "pessoas da terra", provavelmente Diogo e Eva, haja vista que, supõe-se, devem saber mais que os forasteiros. A passagem por Celorico é a motivação inicial para que, a partir daqui, a viajante atente para um fator no mínimo curioso: os nomes dos lugares avistados neste percurso:

Já o nome de Celorico é um pequeno enigma no labirinto vermelho e azul das estradas. Logo adiante, encontraremos outra esfinge no caminho... Mas Portugal está bordado de palavras surpreendentes. Não é só, aqui, Fornos de Algodres, mas ali, Freixo de Espada à Cinta; do outro lado, Santa Comba Dão; lá para cima, Carrazeda de Ansiães... E estes lugares de sonho que se chamam: Barca d'Alva, Ervas Tenras, Vale de Prazeres, Portela do Vento, Penhas Douradas, Rio de Moinhos... Há mesmo um lugar fabuloso que se chama Alfândega da Fé! E o que não daríamos para ficar conversando sobre esses nomes, viajando por dentro das palavras, na paisagem do tempo, muitas vezes mais bela que a paisagem do espaço! (MEIRELES, 1999, p. 96).

Comentando os passeios pelas terras lusíadas, Cecília chegou a destacar que observava entusiasticamente "todos aqueles nomes nas indicações das estradas, [se propondo] a explicar etimologicamente num futuro compêndio para [seu] uso particular" (apud GOUVÊA, 2001, p. 112-113) Examinar os nomes daqueles lugares configurava-se como um divertimento para a cronista, que se surpreendia com as invenções linguísticas portuguesas. Todavia, mais notável que a atenção dispensada a estes nomes é a afirmação ceciliana de que preferiria ficar conversando, "viajando por dentro das palavras, na paisagem do tempo, muitas vezes mais bela que a paisagem do espaço!” Tal afirmação revela o caráter reflexivo das viagens empreendidas pela autora, o que não exige apenas o deslocamento espacial, mas suscita um olhar contemplativo e a consequente observação individual do sujeito sob o espaço avistado.

Todorov afirma existirem "vários tipos de viagem, ou talvez várias categorias que permitem caracterizar as viagens particulares. A oposição mais comum, e que se impõe primeiramente, é $a$ dos planos espiritual e material, ou, se preferirmos, do interior e do exterior" (TODOROV, 1999, p. 15, grifos nossos). Dentre os diferentes tipos de viagem, Todorov destaca duas categorias que refletem a "oposição mais comum": a viagem material ou exterior e a espiritual ou interior. O autor entende que a primeira categoria privilegia a aventura real, a experiência concreta, enquanto a segunda apropria-se do estímulo material, exterior, como uma possibilidade de edificação do espírito. Como exemplo, o autor cita a jornada empreendida pelos cavaleiros da Távola Redonda 
em busca do Santo Graal, que, muito mais do que um deslocamento e uma procura objetiva, era na verdade um encontro com o mítico, uma busca espiritual.

Se remontarmos à distinção de Todorov entre a viagem "interior" e "exterior", percebese que, neste fragmento, Cecília alude à viagem "interior", àquele momento em que os nomes das cidades são apenas o estopim de uma reflexão que conduz o viajante a outras instâncias. Como afirma Arthur Waley, "aquele que faz visitas interiores pode encontrar em si mesmo tudo o que necessita. Essa é a maneira mais elevada de viajar; ao passo que é pobre uma viagem que depende de coisas exteriores" (apud TODOROV, 1999, p. 17) Apesar da motivação exterior, Cecília redimensiona aquilo que observa e chega a abdicar do elemento espacial. A cronista percebe que viajar "por dentro das palavras" ou contemplar a "paisagem do tempo" são movimentos particulares daquele que viaja, "incessantes deslocamentos do real ao imaginário, suscitados pela confrontação do espetáculo e do sonho", como destaca Alain Corbin (1989, p. 195) Entre o real e o imaginado, Cecília desloca-se em meio à poesia das palavras cotidianas, quase imperceptíveis a um passante mais apressado, e paralelamente imagina essas épocas distantes em que um lugar poderia chamar-se "Alfândega da Fé".

Ainda viajando nas palavras, a autora afirma:

Aqui há nomes que devem ter sido inventados para quebrar a cabeça do turista: Alfarela de Jales, Altér do Chão... Outros, que parecem jogos infantis: fiolhoso, gafanhoeira, alto do velão... Os nomes em letras pequeninas, escondidos no intricado desenho do mapa, são, às vezes, mais engraçados: Vera Cruz do Marlemar e este outro: Castanheira de Pêra, — coisas de poeta burlesco, como aquele que cantou:

Quando o sobreiro der baga e o carvalho der cortiça... (MEIRELES, 1999, p. 96).

Aqui, Cecília aponta outras denominações singulares. Como os exemplos citados na crônica, muitos nomes são verdadeiros jogos linguísticos e sonoros, sem coerência ou sentido exato na realidade (tome-se como exemplo "Castanheira de Pera"). Tal ideia é reforçada com a referência aos versos da quadra popular portuguesa, que inverte a lógica da natureza ao alterar o que as árvores (sobreiro e carvalho) produzem.

Deixando um pouco de lado a questão dos nomes, e retomando a observação espacial, Cecília constata que "em Celorico da Beira cai um chuvisco muito agradável, que solta pelo ar um cheiro bom de terra molhada, a sensação de folhas verdes, de frutos em botão, de pesadas casas tranquilas, onde o silêncio é como o tempo de um sino imóvel no campanário" (MEIRELES, 1999, p. 96). A descrição do ambiente privilegia um misto de sensações, como se todos os sentidos se aguçassem na apreensão do que está em volta. Nessa descrição sinestésica do ambiente, percebe-se que a cronista evoca um "lirismo de alquimia verbal, que funde o sensitivo com a fantasia, o concreto com o abstrato, amalgamando os sentidos num fluido 
indiferenciado de visões, sabores e tato, com evidente sentido espiritualizante" (GOUVEIA, 2007, p. 114). Deslocando-se constantemente entre o "sensitivo" e a "fantasia", Cecília Meireles vai delineando sua identidade de viajante e, consequentemente vai construindo seus relatos. Dessa forma, movimentando-se entre o "concreto" e o "abstrato", é possível perceber a chuva e o cheiro de terra molhada, o que acarretará a percepção de "folhas verdes, de frutos em botão". Prosseguindo seu trajeto, a cronista assevera:

A claridade de Guarda obscureceu-se detrás destas nuvens, e vamos aquecer os ossos e a imaginação com um cafezinho servido por um homem de ar muito antigo, — tão antigo que já devia existir na era de D. Sancho, ou, pelo menos na de D. Diniz, o que não faz muita diferença. Pois além de tão antigo, o homem tem seu ar de poeta, coisa, aliás, não muito difícil de encontrar por estes caminhos peninsulares. (E eis um homem tão longe de tudo que nem me pergunta se pode ir para o Brasil!) (MEIRELES, 2009, p. 96-97).

Percebe-se neste fragmento que a viagem adquire sentidos muito particulares para Cecília Meireles. Ela torna-se, também, uma possibilidade de devaneio "sobre a estrada e a travessia, o que vê e o que não vê, o que aprende e o que imagina que sabe, a aparência e a essência, o ser e o devir" (IANNI, 2000, p. 27). Dividida entre tais instâncias da percepção, um simples café torna-se para a viajante uma possibilidade de "aquecer os ossos", e também a "imaginação". Isso porque o "cafezinho", propriamente dito, revigora o físico, mas Cecília esforça-se para também manter animoso seu espírito, tecendo conjecturas acerca do homem "de ar antigo" que serve esse café. Indo além da aparência e buscando também a essência, a cronista julga que o homem tem um "ar de poeta". Característica fácil de ser constatada ao percorrer caminhos carregados de um lirismo natural. Entre a observação da paisagem humana e aquilo que sobre ela se imagina, a autora constata que o homem, alheio ao que o cerca, nem ao menos se interessa pelos forasteiros ou pelo Brasil, apenas cumpre sua função, talvez sem desconfiar das suposições que inspira.

Deixando para trás esse homem enigmático e seguindo viagem, a autora especifica informações temporais e espaciais: "Já vão sendo três e meia, — e, se tudo correr bem, em duas horas passaremos por Coimbra” (MEIRELES, 1999, p. 97). Cecília parece antever aspectos da passagem por esta cidade (utilização de verbos no futuro), ou ainda, usando de artifícios literários, relata fatos já decorridos como se estivessem por acontecer:

Será como se atravessássemos uma velha gravura, que nos parecerá um pouco modernizada. Amaremos essa luz que delicadamente recorta em múltiplos pormenores a encantada e decantada cidade dos estudantes. Acharemos, talvez, o Mondego muito curto de águas. Que é feito das ondas de todos estes rios do mundo? Onde estão as espelhantes curvas do Mondego que há tempos conheci? Recordo-as agora, e, nos seus "saudosos campos", os formosos olhos daquela "que depois de ser morta foi rainha" (MEIRELES, 1999, p. 97). 
Ao atravessar a cidade, notar-se-ia que ares de modernidade a invadiam, mas ainda assim, seria possível amá-la em seus detalhes ressaltados. Cecília inquieta-se ao pensar que, talvez, achará o rio Mondego "muito curto de águas"; possivelmente, um reflexo da modernização apontada no início do parágrafo. Ao avistar o "escasso" rio, a sensação de perda se estende a outros elementos: o que teria acontecido às ondas e às espelhantes curvas do Mondego, também diminutas em sua vitalidade? Recordando-as, evoca-se a figura de Inês de Castro, cujos formosos olhos nunca encontravam o rio enxuto. Constatação evidenciada pela menção aos versos d'Os Lusíadas em "saudosos campos" e "aquela que depois de morta foi rainha". Percebem-se, nesta crônica, referências intertextuais variadas. Sejam fragmentos das cantigas medievais, versos populares ou menção aos clássicos da literatura portuguesa, Cecília promove um entrecruzamento de alusões provenientes de diferentes campos. Estabelecem-se assim conexões que ajudam a reforçar a carga poética de seu discurso.

Ainda em Coimbra, avista-se a "Universidade, lá no alto encastelada", enquanto os viajantes descem "vertiginosamente, como um guerreiro de D. Sancho no encalço do inimigo" (MEIRELES, 1999, p. 97). Partindo de Coimbra, a cronista sente-se comprometida numa verdadeira contenda, "correndo" até Leiria, "cujo famoso castelo já se vai sombreando com a inclinação do sol". Como justifica na sequência, o inimigo perseguido "é o tempo", e na reiteração de tal ideia, Cecília recorre ao título da obra publicada em 1940 pelo poeta Alberto de Serpa: “'Lisboa é longe', — como diz o Alberto de Serpa, — e temos de lá chegar ainda hoje." Envolvida nessa verdadeira batalha contra o tempo, a viajante lastima o fato de também ser preciso dizer adeus ao

castelo e ao pinhal de D. Diniz (“Ai, flores do verde pino!...”); tempos das pastoras "ben talhadas" ("De que morredes, filha, a do corpo velido?"); tempos das auroras claras e da roupa lavada nos rios ("Levantou-s' a velida,/ levantou-s' alva..."). Tudo isso vai saindo do pinhal de Leiria, que o crepúsculo aponta:

Vede la frol do pinho, valha Deus!

Selad o baiozinho

e guiade d'andar.

(MEIRELES, 1999, p. 97).

No tocante às cantigas e à época medieval, Cecília exalta um tempo e uma literatura com os quais se identificava profundamente. O que aparece em seu texto são exatamente traços de sua afetividade pela História e a cultura ancestral, como bem frisa Margarida Maia Gouveia,

Esse viajar pelas culturas, provocado aleatoriamente por viagens reais, é uma "participação intensa das coisas, de fatos, de vidas com os quais nos correspondemos 
desde sempre e para sempre." Essa afetividade, muito cerebralizada e meditativa, é no entanto afetividade, pois que Cecília se sente empolgada pela História e pela cultura de outros povos, como uma vibração que não esconde" (GOUVEIA, 2007, p. 120).

Movida por esta "afetividade", "empolgada pela História", a cronista refere-se, neste trecho, ao "castelo" e ao "pinhal" de D. Diniz. No castelo de Leiria, o rei teria residido por diversas ocasiões. Já a alusão ao pinhal se deve ao fato de que D. Diniz, conhecido como "O Lavrador", teria concluído o plano de D. Afonso III, o qual mandara plantar uma verdadeira floresta de pinhais na região. D. Diniz também é reconhecido como trovador, e a ele atribui-se a autoria de aproximadamente 137 cantigas, dentre elas a popular "Ai, flores do verde pino", mencionada no texto. Cecília cita alguns trechos de outras cantigas medievais enquanto se despede da cidade e dos tempos de "pastoras 'ben talhadas', "tempo das auroras claras, e da roupa lavada nos rios". Percebe-se aqui, como afirma Alfredo Bosi, uma "identificação entre a história dos lugares e a sensibilidade da artista" (BOSI, 2007, p. 21), que capta nos instantes passageiros da viagem significativas referências para a construção de seu relato.

Citando mais um fragmento de cantiga, em que se menciona o "baiozinho", Cecília lembra que o seu "baiozinho" está "bebendo gasolina" tentando vencer a estrada antes da noite, percorrendo um caminho "interminável, interminável, interminável, para quem começou a viajar às nove da manhã em Salamanca...” (MEIRELES, 1999, p. 98). O cansaço da viagem é evidente e retratado de maneira sincera nesta crônica em particular; afinal, ainda que a paisagem seja admirável e que os encantos do caminho conquistem a atenção, o que se deseja é chegar finalmente ao destino. Como afirma Cecília Meireles na crônica "Direção leste", "o amor pelas viagens, para quase toda a gente não está no viajar, mas no chegar” (MEIRELES, 1999, p. 153). Todavia, até o "chegar", a viajante e seus companheiros ainda enfrentariam um percurso considerável, como evidenciado adiante:

E assim se descobrem, no fim do dia, as agulhas da Batalha; e, daí a pouco, sabese que é Alcobaça, e, mais adiante, Caldas da Rainha, e já se faz sombra por toda a parte, uma sombra de prata, que vai consumindo lentamente os contornos, as cores, e apontando Lisboa, Lisboa, Lisboa, - cidade encantada que não aparece nunca (MEIRELES, 1999, p. 98).

A tarde já esmorece quando o grupo passa por outras regiões portuguesas, como a Batalha com suas "agulhas" (referência à arquitetura do Mosteiro da Batalha), Alcobaça e Caldas da Rainha. Lisboa é apenas apontada em seus contornos sem, contudo, aparecer. Quando finalmente a cidade é avistada, a cronista é arrebatada por uma espécie de enlevo: "E afinal, aparece, oh! - e ainda não é tão tarde que não esteja um amigo acordado para ouvir a odisseia destes viajantes-fantasmas, tontos de vencerem, no mesmo dia, as terras de Espanha e as areias de Portugal” (MEIRELES, 1999, p. 98). Valendo-se dos versos populares, Cecília deixa entrever 
que o prazer da chegada acaba sublimando o cansaço, o esgotamento da viagem. Tanto é assim que ela ainda tem esperança de encontrar alguém acordado para narrar sua aventura.

Percebe-se que a crônica acaba ganhando outra dimensão quando finalmente a "batalha" é vencida e adentra-se em Lisboa. A admiração por Portugal, alimentada durante todo o percurso, e que atinge seu apogeu no momento da chegada à capital, pode agora ser externada em toda sua vitalidade. Dessa forma, envolvida num misto de deleite e alívio, Cecília reafirma seu carinho pelas terras lusitanas, destacando as compensações advindas do longo trajeto percorrido:

\begin{abstract}
Além das famosas areias de ouro, Portugal possui três coisas muito amoráveis: os nossos amigos, a paisagem e as criaturas simples. Os amigos são sempre pessoas maravilhosas, por toda parte. Paisagens, também se encontram belíssimas, por muitos lados. As pessoas simples, embora nem sempre com a mesma simpatia, não são, igualmente, exclusividade de Portugal. Mas tudo isso ao mesmo tempo, e em número razoável, é uma felicidade que compensa vir de Salamanca a Lisboa, sobretudo quando se cultiva a disciplina de ignorar completamente todas as demais coisas que não possam entrar na órbita do nosso perfeito amor (MEIRELES, 1999, p. 98).
\end{abstract}

Como afirmado anteriormente, Cecília Meireles sempre manteve uma relação de afetividade com Portugal, cultivando inúmeros amigos, admirando a beleza das terras lusitanas, observando com sensibilidade os personagens do presente e do passado que ajudam a compor este painel. Ao elencar os três elementos mencionados, a autora revela um pouco das particularidades que compõem sua essência viajante. Tal personalidade é definida ainda mais quando Cecília demonstra que a experiência da viagem depende da própria disponibilidade do viajante em priorizar o agradável e o belo.

A afirmação ceciliana ("ignorar todas as demais coisas que não possam entrar na órbita do nosso perfeito amor") revela muito mais do que uma possível ideia de afastamento da realidade ou de certa alienação do viajante que só percebe aquilo que lhe é conveniente. Na verdade, a sentença reforça a imagem de que o ato de viajar em sua dimensão subjetiva e pessoal, como percurso físico, mas também simbólico, congrega indissoluvelmente as categorias de percepção que vão do "exterior"/"material" até o "interior"/"espiritual". Como afirma Margarida Gouveia, no tocante à cronista,

as numerosas viagens que realiza à Índia, Portugal, Itália, Holanda, mereceriam registro poético que curiosamente não descreve paisagens nem se fixa em imagens exteriores. Cada viagem é pretexto para meditações que para Cecília transformam o real num espaço feito de História, lembranças, sonhos, sensações" (GOUVEIA, 2002, p. 169).

Livre do peso das "imagens exteriores", Cecília valoriza a viagem muito mais em sua dimensão "interior", e assim é possível "ignorar", como afirma a autora, tudo aquilo que 
não se insere nessa categoria de percepção. Dessa forma, mesmo que circunstâncias adversas surjam ao longo do caminho, a experiência da viagem ainda pode ser sublime caso o deseje o viajante. Basta, para isso, minimizar os efeitos do deslocamento "real", enfatizando os aspectos de ordem mais elevada, sejam momentos de prazer, aprendizado, reflexão, meditação ou apreciação do belo.

Dessa forma, a cronista não se atém à fadiga da viagem, exaltando apenas os momentos afáveis experimentados ao longo do trajeto. Enredada neste misto de encantamento e êxtase, celebrando a chegada a Lisboa, Cecília encerra o texto fazendo um brinde às maravilhas portuguesas:

Assim, pois, se, em lugar de uma xícara de chá, estivéssemos, neste momento, diante de um copo de vinho, levantaríamos um brinde aos velhos e queridos amigos, às águas, às serras, aos pinhais, aos muros de pedra, aos barcos, aos lavradores, aos pastores, a toda essa boa gente que já está dormindo a esta hora, - e aos poetas que devem andar acordados, de olhos abertos para a noite, para estas estrelas, para a sua alma, para sua memória... (MEIRELES, 1999, p. 98).

Percebe-se que o "brinde" proposto pela autora reitera as "três coisas muito amoráveis" destacadas anteriormente como qualidades portuguesas: os amigos, a paisagem (águas, serras, pinhais) e as criaturas simples (lavradores, pastores). Cecília celebra também outro personagem lusitano: o poeta. Assim como a própria autora, enquanto todos os outros descansam, o poeta permanece acordado, "de olhos abertos", num processo incansável de reflexão sobre o mundo e sobre si mesmo. Inserido nesta outra categoria humana, o poeta é citado em momentos distintos das crônicas cecilianas, sendo destacado, por exemplo, como "uma criatura de eleição, um inspirado, um mensageiro de avisos sobre-humanos” (MEIRELES, 1999, p. 211), ou ainda, como "os grandes sugestionadores de uma realidade mais bela" (MEIRELES, 2007, p. 22). As definições refletem o apreço da autora pela atividade poética e a celebração dessa arte que envolve emoções tão profundas. Num país como Portugal, sempre associado ao lirismo e à subjetividade, que parecem brotar naturalmente em cada recanto, não causa surpresa que Cecília encerre a presente crônica enaltecendo o ofício do poeta. Observando a "noite", as "estrelas", a "sua alma" ou "sua memória", o poeta volta-se para o exterior e para o interior de si mesmo e nesse eterno trânsito encontra maneiras de transmitir beleza e sensibilidade, enriquecendo assim a existência humana.

\section{Referências}

BOSI, Alfredo. Em torno da poesia de Cecília Meireles. In: GOUVÊA, Leila V. B. (Org.). Ensaios sobre Cecília Meireles. São Paulo: Humanitas: Fapesp, 2007.

CORBIN, Alain. Território vazio. São Paulo: Companhia das Letras, 1989. 
GOUVÊA, Leila V. B. Cecília em Portugal. São Paulo: Iluminuras, 2001.

. Pensamento e "lirismo puro” na poesia de Cecília Meireles. São Paulo: Edusp, 2008.

GOUVEIA, Margarida Maia. Cecília Meireles - uma poética do “eterno instante”. Lisboa: Imprensa Nacional - Casa da Moeda, 2002.

. “As viagens de Cecília Meireles”. In: GOUVÊA, Leila V.B, (org.) Ensaios sobre Cecília Meireles. São Paulo: Humanitas; Fapesp, 2007.

IANNI, Octavio. Enigmas da Modernidade - Mundo. Rio de Janeiro: Civilização Brasileira, 2000.

MEIRELES, Cecília. Crônicas de viagem. Rio de Janeiro: Nova Fronteira, 1999. v. 2.

. Episódio humano. Rio de Janeiro: Desiderata: Batel, 2007.

SANCHES NETO, Miguel. "Cecília Meireles e o tempo inteiriço" In: MEIRELES, Cecília. Poesia completa. vol.1. Org. Antonio Carlos Secchin. Rio de Janeiro: Nova Fronteira, 2001.

TODOROV, Tzvetvan. “A viagem e seu relato”. In: Revista de Letras, v. 39, n.1, p. 13-24, São Paulo: Unesp, 1999.

\section{Minicurrículo}

Docente da área de Literatura, no curso de Letras, da Universidade Federal de Alagoas, campus Arapiraca. É Doutora em Letras com a tese intitulada "Navegando em mares lusitanos: diálogos transatlânticos entre Cecília Meireles e Portugal" defendida na Universidade Federal do Paraná com período de bolsa sanduíche na Universidade de Lisboa. Possui Mestrado em Letras pela Universidade Federal do Paraná e Graduação em Letras Português e suas Literaturas pela Universidade Estadual do Centro-Oeste. 